\title{
Mental Health at Workplace: A Bibliometric Analysis of Literature from Canada
}

Ravi Dwivedula

Department of Business Administration-Faculty of Arts, Brandon University, Canada

\begin{tabular}{ll} 
ARTICLE INFO & ABSTRACT \\
\cline { 2 - 2 } $\begin{array}{l}\text { Keywords: } \\
\text { Mental Health }\end{array}$ & $\begin{array}{l}\text { The purpose of this paper is to identify and review the research themes } \\
\text { in the area of mental health in workplace. I conduct a bibliometric } \\
\text { Canada }\end{array}$ \\
$\begin{array}{l}\text { Bibliometric Analysis of } 219 \text { peer-reviewed articles specific to research conducted in } \\
\text { Qualitative Research }\end{array}$ & $\begin{array}{l}\text { Canada. The articles are extracted from EBSCO using the key words } \\
\text { "mental health" and "workplace" and published between the years } 2000\end{array}$ \\
and 2020. A qualitative research technique - 'co-occurrence of key \\
words' is used to identify the most relevant key words in the theoretical \\
corpus of 219 articles. Most frequently occurring words are clustered \\
together forming a research theme. Five research themes- healthcare \\
management, organizational context and support, psychological issues, \\
methodology \& research design, and Participants are identified. This \\
research makes a significant academic contribution in providing \\
directions for future research on the topic of mental health in \\
organizations. From the practitioner viewpoint, it draws the attention of \\
healthcare professionals to some of the more recent practices in \\
organizations that address the important issue of mental health.
\end{tabular}

1. Introduction

Mental illness and mental health problems are identified among leading causes of death and disability in the developed countries. They are also more common than physical ailments in the workforce (Kelloway, 2018). There is increased awareness of mental health issues in organizations. This has lead to a wide variety of employee assistance programs, changes to mental health policies, and educating the employees. These are but a few of the comprehensive mental health strategies introduced by the organizations today (Kelloway, 2018). On the other hand, workplace mental health is also an expanding practice area for healthcare providers. Some of the challenges such as inadequate funding, and lack of training are identified as reasons for mental ill-health among healthcare professionals (Moll et al, 2018). Despite this growing awareness of the importance of workplace mental health and its causes, there is a gap in the literature regarding pointers to the theoretical base. Extant literature identifies the causes of workplace stress, and interventions to overcome mental health problems. However, the literature is sporadic thus preventing the consolidation of research themes. Specifically, in case of Canada, research on mental health issues at workplace may have been lacking as compared to other regions and countries. A cursory search on a reputable research database such as EBSCO reveals 221 peer-reviewed articles on this theme. This falls short in comparison to the studies being conducted in other regions such as United Kingdom (674 papers), mainland Europe (555 research articles), and USA (514 articles). Therefore, in this paper, my purpose is to address this gap.

The research question asked is what is the status of literature on mental health issues at workplace in Canadian organizations?

*Corresponding author E-mail address: DwivedulaR@BrandonU.ca 
The paper is organized into the following sections. Section 1-literature review provides an overview of peer-reviewed articles published in the field. Specifically, some of the major research themes, and methodologies adopted to study mental health at workplace will be presented. Section-2 methodology discusses the qualitative research technique-" co-occurrence of key words' used to analyze the literature. Section 3 -Findings, presents the research themes that are extracted from the theoretical corpus using the co-occurrence of key words. Section 4Discussion presents an elaborate analysis and description of the research themes. This is followed by conclusion.

\section{Literature Review}

Mental health at workplace has received modest attention in Canada. The enactment of National Standard for Psychological Health and Safety, 'Mental health first Aid', are some of the initiatives from Canada that recognize the need to address mental health issues at work place. A multitude of areas such as mental disorders (O'Hagan, Bailantyne, Vienneau, 2012; Kelloway, 2018), workplace practices directed at employee wellness (Moll, 2018; Cavanaugh, 2014), and occupational safety (Malachowski, Kirsh, McCeachen, 2017) have been extensively researched. Efforts to consolidate the literature on mental health issues at workplace though sporadic, appear in more recent research. For example, Lanctôt, and Guay (2014) conduct a systematic review of literature on workplace violence for its effects on physical, psychological, and emotional health of the employees. Eaton, Ohan, and Dear (2015) provide a systematic literature review on stigmatization of alcohol, and other drug (AOD) workers and how it impedes their functioning. Foster et, al (2019) synthesize state of knowledge on resilience in mental health nursing. Examining the literature on burnout among physicians (Rotenstein et al, 2018), and literature on compassion failure among healthcare professionals due to fatigue (Sorenson et al, 2016) are some of the other examples which aim to capture the status of literature on this topic. However, similar research in the Canadian context is limited. Canadian Journal of Administrative Sciences dedicated a special issue to workplace mental health research (kelloway, 2018). Koopmans (2017) conduct a literature review on causes of suicide among emergency response service providers in Canada. The current paper advances this line of research by consolidating the research studies on this topic from Canada.

\section{Methodology}

VosViewer 16.1.8 was used to conduct the content analysis. The specific technique is called co-occurrence of key words. 155 peer-reviewed articles from EBSCOhost were extracted and considered using the string "workplace" AND "mental health". Only studies from Canada were considered. The years of publication was from 2000 to 2020. The co-occurrence of key words revealed a five-cluster model which groups 103 items. Each key word should occur for a minimum of four times with one another key word from the theoretical corpus. Key words that occur together most frequently are then filtered from the set which gave us 103 key words. These were used in the final analysis. The following table 1 provides a summary of the search strategy.

Table 1.

Search strategy to extract peer-reviewed articles

\begin{tabular}{ll}
\hline Search strategy & Action \\
\hline Academic database searched & EBSCOhost \\
\hline Target items & Peer-reviewed journal articles \\
\hline Search applied to & Entire article (includes text, title, subject terms, and abstract) \\
\hline Language & English \\
\hline
\end{tabular}




\begin{tabular}{|c|c|}
\hline Search strategy & Action \\
\hline Search string & $\begin{array}{l}\text { "mental health" and "workplace"; only those peer-reviewed studies that } \\
\text { were conducted in Canada or set in the context of Canadian } \\
\text { organizations were considered }\end{array}$ \\
\hline Publication period & $2000-2001$ \\
\hline Inclusion criteria & Peer-reviewed academic papers that satisfy the search string \\
\hline Exclusion criteria & $\begin{array}{l}\text { Papers that do not focus on mental health AND workplace } \\
\text { Conference papers, book reviews, editorial material, news items, notes, } \\
\text { letters, book chapters and other such documents which were not peer- } \\
\text { reviewed articles were excluded from analysis }\end{array}$ \\
\hline $\begin{array}{l}\text { Final number of peer-reviewed } \\
\text { articles considered for analysis }\end{array}$ & ( \\
\hline $\begin{array}{l}\text { List of journals from which the } \\
\text { articles were sourced }\end{array}$ & $\begin{array}{l}\text { Journal of workplace behavior health, Canadian journal of psychiatry, } \\
\text { Oohna journal, Work, Journal of medical internet research, Canadian } \\
\text { journal of community mental health, Canadian journal of ageing, Social } \\
\text { indicators research, Canadian journal of medical laboratory science, } \\
\text { Canadian journal of occupational therapy, Canadian journal of public } \\
\text { health, plans \&trusts, Canadian journal of nursing research, Canadian } \\
\text { nurse, Canadian psychology, Canadian public policy, Canadian journal } \\
\text { of emergency medicine, Canadian medical association journal, Social } \\
\text { science and medicine, American journal of public health, Employee } \\
\text { responsibilities and rights journal, Journal of applied social psychology, } \\
\text { Journal of college student psychotherapy, Journal of loss and trauma, } \\
\text { Ageing and society, Aging and mental health, British journal of } \\
\text { management, Canadian journal of administrative sciences, work \& } \\
\text { stress, Journal of ethics in mental health }\end{array}$ \\
\hline
\end{tabular}

\section{Findings}

The results of the analysis are summarized in a social graph (figure 1). Five major research themes, each represented by a unique color point to the underlying research themes. In the network visualization, the terms are represented by circles and corresponding labels. The size of the circle and the label is indicative if its weightage and hence importance. The higher the weight of a term, the larger will be the size of the label. The distance between the terms indicates the relatedness of the terms with respect to co-occurrence links. In general, the closer the two terms are, the stronger is their relatedness.

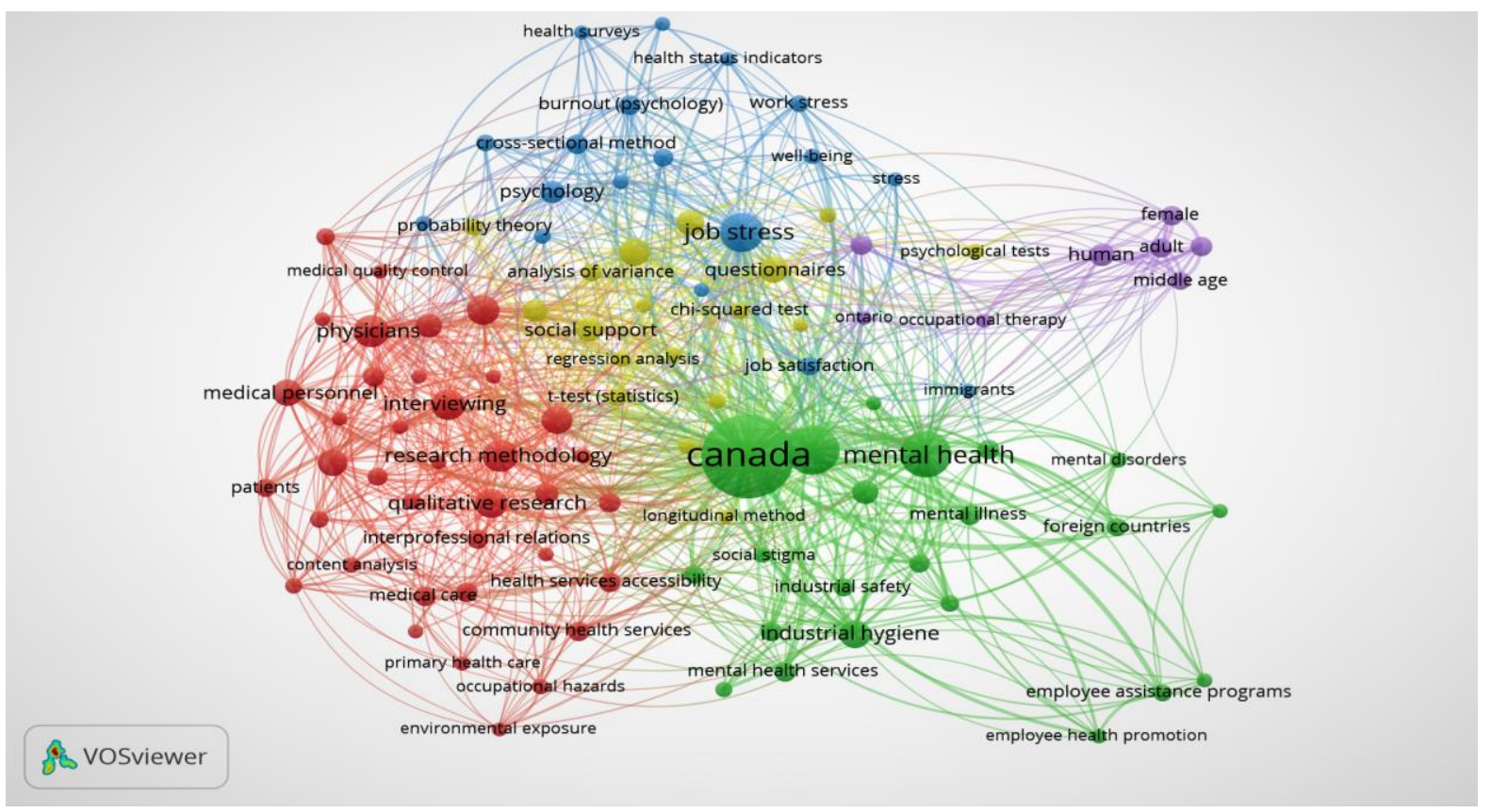

Figure 1. Social graph of research themes-Mental Health at Workplace 
The research themes are organized into five clusters which are summarized in table 2 below. These themes are 'healthcare management', 'organizational context \& support', 'psychological issues', 'methodology', and 'participants'.

Table 2.

Research themes with pertinent key words

\begin{tabular}{ll}
\hline Cluster theme & Key words \\
\hline $\begin{array}{l}\text { Cluster 1. } \\
\text { Healthcare } \\
\text { management }\end{array}$ & $\begin{array}{l}\text { Environmental exposure, healthcare teams, health services accessibility, hospital medical staff, } \\
\text { interprofessional relations, medical care, medical cooperation, medical personnel, medical } \\
\text { quality control, nurses, occupational hazards, occupational roles, patients, physicians, primary } \\
\text { health care, professional practice, quality assurance, research funding, research methodology, } \\
\text { teams in the workplace, violence in the workplace, working hours }\end{array}$ \\
\hline $\begin{array}{l}\text { Cluster 2. } \\
\text { Organizational } \\
\text { context \& support }\end{array}$ & $\begin{array}{l}\text { Counseling of employees, depression, employee assistance programs, health promotion, } \\
\text { industrial hygiene, industrial safety, mental depression, mental disorders, mental health, mental } \\
\text { health services, mental illness, occupational health, organizational culture, personnel } \\
\text { management, social stigma, work environment, workplace }\end{array}$ \\
\hline $\begin{array}{l}\text { Cluster 3. } \\
\text { Psychological } \\
\text { issues }\end{array}$ & $\begin{array}{l}\text { Burnout, work overload, health, health status indicators, health surveys, job satisfaction, job } \\
\text { stress, psychology, self-efficacy, stress, well-being, work, work stress }\end{array}$ \\
\hline $\begin{array}{l}\text { Cluster 4. } \\
\text { Methodology }\end{array}$ & $\begin{array}{l}\text { Analysis of variance, chi-square test, confidence intervals, correlation, descriptive analysis } \\
\text { software, descriptive statistics, longitudinal method, multiple regression analysis, probability } \\
\text { theory, questionnaires, surveys, t-test }\end{array}$ \\
\hline $\begin{array}{l}\text { Cluster 5. } \\
\text { Participants }\end{array}$ & Adult, employment, female, human, male, middle age, occupational therapy \\
\hline
\end{tabular}

\section{Discussion}

\subsection{Cluster 1. Healthcare Management}

Workplace stress significantly affects the work output. This is even more conspicuous in the healthcare industry. Studies on healthcare professionals revealed that stress affects the quality of care (Karadzinska, Basarovska, Mijakoski, Minov, Stoleski, Angeleska, \& Atanasovska, 2014; Gevaux, \& Petty, 2018). Some of these factors are related to the availability of resourcesmedical equipment and supplies, and qualified personnel. Other factors were related to their occupational demands such as adequacy of time, working hours, and schedules. Opportunities for professional development, and continuous training also has an important role in reducing the stress and providing better healthcare service. Furthermore, research also shows that organizational initiatives such as employee assistance programs significantly reduced psychological distress, symptoms of depression, and anxiety while increasing work engagement (Milot, 2019). For the successful planning, and implementation of such practices, a holistic view that captures the interests of all stakeholders concerned-recipients, service providers, and organizational leaders, need to be held (Moll, VandenBussche, Brooks, Kirsh, Stuart, Patten, \& MacDermid, 2018).

\subsection{Cluster 2. Organizational Context and Support}

Employment is a major issue affecting the health and well-being of an individual. Yet, maintaining a place in the workforce for those who have mental illness has been a challenge. Individuals who experience mental illness (also termed mental health consumers) face social discrimination and denial of employment opportunities (Kirsh, 2000). Furthermore, organizations and managers are cognizant of these issues among their workforce. While conscious efforts to address these issues may have been wanting, employee well-ness programs directed at improving the psychological and physiological health of the employees is a step in the right direction. While there are reports that employee wellness programs do not yield the intended results of improved health and reduced stress among the employees (Bakker, Demerouti, Taris, Schaufeli, \& Schreurs, 2003), some positive outcomes of such programs 
have been reported (Mattke, Liu, Caloyeras, Huang, Van Busum, Khodyakov, \& Shier, 2003 cited in Ott-Holland, Shepherd, \& Ryan, 2019). In advancing the employee wellness programs in the organization, personnel management plays an important role. Gavino, Wayne, and Erdogan (2012) categorized human resource practices into two-transactional (those practices which are statutory in nature), and discretionary (non-obligatory practices followed by the organization). They posit that the discretionary human resource practices are capable of having a strong effect on the employees' well-being. Wellness programs can be construed as discretionary human resource practices. Nishii and Wright (2008) offer a complementing argument. They conclude that in order for the employee wellness programs to have the desired positive effect on the employees, their positive interpretation by the employees is important. If the wellness programs are understood as an insincere effort and cost control exercise by the employees, it undermines the credibility of the program. Regular follow up and employee counseling becomes important to attain enduring benefits to the employees (Milot, 2019). Employees should be counseled and educated on various issues pertaining to their work environment and nature of work for the success of the intervention.

\subsection{Cluster 3. Psychological Issues}

Research on psychological issues relevant to workplace have increased over the years. Numerous organization factors such as burnout, increasing workload (Garcia, McGreary, McGreary, Finley, \& Peterson, 2014), employee morale (Kendrick, 2017), and workplace discrimination (Velez, Cox Jr, Polihronakis, \& Moradi, 2018) have been investigated for their effect on employee performance, ad well-being. Contemporary research also highlights the serious mental health issues that physicians, and allied healthcare professionals face (Grace, \& VanHeauleven, 2019). Contributing factors to stress among healthcare professionals are explicated across three domains- personal, job related, and organization specific (Eliacin, Flaagan, Monroe-DeVita, Wasmuth, Salyers, \& Rollins, 2018). While the larger aim of the healthcare industry has bee to improve patient experience, and reduce the cost of care, researchers also called for improving healthcare staff experience for effective delivery (Brand, Thompson, Fleming, Carroll, Bethel, \& Wyatt, 2017). Healthcare providers have a need to evaluate and describe the mental health of their staff regularly (Renwick, Lavelle, James, Stewart, Richardson, \& Bowers, 2019). Monitoring the mental health of the employees through formal studies such as surveys will enable the organizations to identify the early warning signs. Furthermore, the effectiveness of the interventions such as employee wellness programs can also be accurately assessed (Emerson, Merrill, Shedd, Bilder, \& Siddharth, 2017).

\subsection{Cluster 4. Methodology}

Measurement and analysis of mental health issues has been driven by evidence-based evaluation of the interventions. A variety of rigorous research designs enriched our understanding of the issues objectively. For example, LaMontagne et al (2016) used a sampling technique called cluster-randomized trial (where a random sample of organizational units receive training on employee wellness and the employees' effectiveness receiving this training is compared to another organizational unit whose employees do not receive the training) to know the effects of psychological working conditions and mental-health awareness on employee performance. Other methods to study self-reported stress among employees and well-being using cross-sectional survey of employees (Kermott, Johnson, Sood, Jenkins, \& Sood, 2019), long term effects of organizational change on employee stress observed in a longitudinal study (Loretto, Platt, \& Popham, 2010), and predicting the relationship between hiring of peer support workers and mental health recovery of employees using multiple regression analysis (Clossey, Solomon, Hu, Gillen, \& Zinn, 2018). Case studies of organizations were also developed. For example, Fleury, Grenier, and Bamvita (2017) 
compared job satisfaction among three categories of healthcare professionals working in a Quebec hospital-nurses, psychotherapists/psychoanalysts, and social workers. Multivariate analysis, and structural equation modeling techniques were used to conclusively predict the overall employee wellness and satisfaction of employees. Using such rigorous statistical techniques, and in some cases, adapting (study) designs to know how the interventions reduced psychological risks ad improved working relationships among employees continues to lead to a better understanding of mental health issues at workplace (Biron, Ivors, \& Brun, 2016).

\subsection{Cluster 5. Subjects}

Research suggests that a growing number of employees are reporting high levels of workfamily conflict (Higgins, Duxbury, \& Julien, 2014). Work-family conflict occurs when the demands of work and non-work roles are incompatible (Greenhaus, \& Beutell, 1985 as cited in Higgins, Duxbury, \& Julien, 2014). A substantial body of empirical analysis links work-life conflict to negative outcomes such as poor physical and mental health, lower job satisfaction, and lower organizational commitment. Especially in the context of work-family conflict, gender-based studies are useful to know how individuals across genders perceive work-family conflict and therefore its outcomes (Jian, 2006). Apart from gender, marital problems, and stressful financial condition are also significant determinants of work-life conflict (Marchand, Drapeau, \& Beaulieu-Prévost, 2012). Thus, most available research then points to work stressors as a cause of mental health problems. The reciprocal relationship is also widely acknowledged in research. Workers with poor health conditions perceiving the same working conditions negatively as compared to healthy workers (de Lang et al, 2005). Thus, it may be important to consider the effects of demographics to better understand the relation between work stressors and their effects on the individual subjects. Using this argument, there have been studies that measure the role of social class on one's perceived work stress, and mental health (c.f. Kunst et al, 2004; Muntaner et al, 2003). Other demographic variables such as age (Brown, \& Pashniak, 2018), and career stage (early, mid-career, or late career- Shippee, Wilkinson, Schafer, \& Shippee, 2019; Nørøxe, Pedersen, Bro, \& Vedsted, 2018). Thus, it becomes imperative to consider the demographic data about the subjects to comprehensively understand the implications of workplace stressors for the individual's mental health and organization's effectiveness.

\subsection{Systemic View of Research on Mental Health at Workplace}

Workplaces with a positive approach to mental health are able to perform better, engage and retain talent, and reduce various risks such as employee grievances, absenteeism, and disability. The themes extracted from extant literature suggests that addressing mental health issues at workplace goes beyond the traditional understanding of creating a psychologically healthy, and safe environment. A systemic view of psychological, organizational, and occupational issues is essential to address the challenges that emanate from mental health problems at work.

The profound influence of workplace factors on mental health of the employees has been extensively investigated in the healthcare industry. Numerous studies have shown that workplace settings such as physical violence, especially patient violence is a leading cause of employee stress, and turnover (Lamothe, Boyer, \& Guay, 2021; Zhao et.al, 2015). Other consequences include lower level of psychological wellbeing among healthcare professionals (Zhao et.al, 2015), post-traumatic stress disorder (PTSD, Jacobwitz, 2013), and lower organizational commitment (Laschinger, \&Grau, 2012). It also has consequences for the quality of medical treatment where worker reassignment and duty changes (Gerberich et.al, 2004) has led to the healthcare professional's inability to maintain therapeutic alliance with their patients (Slemon, Jenkins, \& Bungay, 2017). One response to overcome these issues has been to usher in innovative practices t manage medical personnel, physicians, and other such 
healthcare professionals (Osborne et al., 2015). One such example is the development of indicators to measure the quality of healthcare services. These included metrics such as accessibility of healthcare services, creating healthy workplace for the professionals, optimal utilization of resources, and monitoring the delivery of (healthcare) services scientifically (Schull et al., 2011).

The success of such management practices is contingent upon organizational support. Organizational scientists have long established that employees who feel supported at work report higher levels of wellbeing (Kurtessis et al., 2017).

Extant research points to definitive conclusion that employees who feel supported at work report higher levels of job satisfaction, and tend to be protected from the effects of mental depression, and job burnout (Galián-Muñoz et al., 2016). The organization' culture through its influence on job demands, rewards, fairness towards employees, and supportive work practices is instrumental in creating psychological safety for employees (Shane, Arnold, \& GermAnn, 2012). Such practices have been defined as a distinct construct called 'psychological safety climate (PSC)' which is the readiness of management to prevent and respond to stressful working conditions (Havermans et al., 2017). Specifically, personnel management practices such as flexible work arrangements (Higgins, Duxbury, \& Julien, 2014), promoting industrial hygiene and safe working practices to reduce workplace injuries (Kelloway, \& Hepburn, 2010), employee training, and fair treatment of employees without discrimination (Seung-Wan, \& SuDol, 2016) are important to ameliorate the effects of workplace stress.

So far, we have come to understand that addressing the problem of mental health requires transcending the individual- organization boundary. Workplace practices that address mental health are specific to the individual psyche as much as they are integrated with the organization's practices. Therefore, from the methodological point of view, call to adopt a multi-level approach: individual, working group, organizational, and the broader societal factors have been given (Martin et al., 2016).

Studies pertaining to development of standards at the national level, and their acceptance across organizations in the country (Sheikh, Smail-Crevier, \& Wang, 2018), the effects of sociopolitical climate when implementing the national standard for psychological health and safety at the workplace (Malachowski, Kirsh, \& Mceachen, 2017), educating employers to overcome the stigma surrounding mental health issues by Mental Health Commission of Canada (Szeto et al., 2019), the effects of work-family conflict on the mental health of individuals (Li, \& Lee, 2020) are some examples that reflect the broad range of units of analysis- society, organization, and individual considered in these research studies.

The robust research methods used in these studies are also instrumental in significantly advancing our understanding of these issues. Quantitative research methods and empirical studies have dominated the research landscape of mental health studies. Longitudinal studies to determine the long-term effects of perceived financial strain and age discrimination at work on the mental health of women (Shippee et al., 2019), determining the long-term benefits of leaders' training in organization on mental health issues (Dimoff, \& Kelloway, 2019).Methods such as multi-level modelling were used I longitudinal studies to study the impact of mental health training on employee outcomes such as work engagement, mental health knowledge, and stigma (Carleton et al., 2018). Surveys that used instruments such as job content questionnaire (Rueda et al., 2015; Machand, \& Blanc, 2011), acute disorder scale (Lamothe, Boyer, \& Guay, 2021), personal depression stigma scale (Dimoff, \& Kelloway, 2019), authentic leadership scale (Read,\& Laschinger,2015), mental health inventory (Read, \& Laschinger, 2015) investigated variables such as psychological distress (Lamothe, Boyer, \& Guay, 2021), employee productivity (Dimoff, \& Kelloway, 2019), and work arrangements (Kleiner, Schunck, \& Schömann, 2015). These studies when grounded in sound statistical methods such as probability theory (Wathen, MacGregor, \& MacQuarrie, 2018; Sockalingam 
et al., 2017), and multiple regression analysis (Tianan et al., 2020) reveal insightful relations between the variables.

\section{Conclusion}

VOSviewer creates distance-based map of the network where the distance between the nodes indicates their level of proximity. The colors of the network in addition to indicating the cluster, also demonstrate areas with the largest concentration of citations. From the social graph, it is evident that cluster 1 - 'healthcare management' (indicated in red), and cluster 2- 'organizational context \& support' (shown in green) have the largest concentration of citations, and therefore the most influential areas of study related to mental health studies at workplace. The distancebased map also indicates terms with no strong connections to other key areas of mental health research. Some of these terms are 'employee health promotion', 'employee assistance programs', 'environmental exposure', 'occupational hazards', 'medical quality control', 'work stress', and 'female'. This then indicates research gaps that need to be addressed. For example, research that may focus on employee assistance programs specifically targeted at women workers, the effects of prolonged exposure to hazardous environment on mental health of the individual, review of metrics that indicate mental health could offer promising research agendas for the future.

Extant literature and practice consistently point to the relation between work environment and mental health of the employees. The overwhelming state of emotional exhaustion, depersonalization that results from long term work stress (Hinderer et al, 2014) also has important ramifications for the organization in terms of high employee turnover, and lower job productivity (Dyrbye, \& Shanafelt, 2016). From the Canadian perspective, I believe this is first of such studies that attempts to review the underlying research themes. The study highlights specific sectors, psychological issues, workplace practices, and study protocols related to the topic of mental health at workplace. I believe this initial dialog will spark further interest and research on the topic along specific directions presented in this paper.

\section{References}

Biron, C., Ivers, H., \& Brun, J. (2016). Capturing the Active Ingredients of Multicomponent Participatory Organizational Stress Interventions Using an Adapted Study Design. Stress \& Health: Journal of the International Society for the Investigation of Stress, 32(4), 275-284. https://doi.org/10.1002/smi.2700

Bakker, A. B., Demerouti, E., Taris, T., Schaufeli, W. B., \& Schreurs, P. (2003). A multi-group analysis of the Job Demands-Resources model in four home care organizations. International Journal of Stress Management, 10, 16-38. 10.1037/1072-5245.10.1.16

Brand S. L., Thompson C.J., Fleming L.E., Carroll, L., Bethel, A., \& Wyatt, K. (2017). Wholesystem approaches to improving the health and wellbeing of healthcare workers: A systematic review. PLoS ONE 12(12): e0188418. https://doi.org/10.1371/journal.pone.0188418

Brown, C. A., \& Pashniak, L. M. (2018). Psychological health and occupational therapists: Burnout, engagement and work addiction. Work, 60 (4), 513-525. https://doi.org/10.3233/WOR-182759

Carleton, R. N., Korol, S., Mason, J. E., Hozempa, K., Anderson, G. S., Jones, N. A., Dobson, K. S., Szeto, A., \& Bailey, S. (2018). A longitudinal assessment of the road to mental readiness training among municipal police. Cognitive Behaviour Therapy, 47 (6), 508-528. https://doi-org.berlioz.brandonu.ca/10.1080/16506073.2018.1475504

Clossey, L., Solomon, P., Hu, C., Gillen, J., \& Zinn, M. (2018). Predicting job satisfaction of mental health peer support workers (PSWs). Social Work in Mental Health, 16 (6), 679. https://doi.org/10.1080/15332985.2018.1483463 
De Lange, A. H., Taris, T. W., Kompier, M. A., Houtman, I. L., \& Bongers, P. M. (2005). Different mechanisms to explain the reversed effects of mental health on work characteristics. Scandinavia Journal of Work, Evironment, and Health, 31 (1), 3-14

Dimoff, J. K., \& Kelloway, E. K. (2019). With a little help from my boss: The impact of workplace mental health training on leader behaviors and employee resource utilization. Journal of Occupational Health Psychology, 24 (1), 4-19. https://doi-org.berlioz.brandonu.ca/10.1037/ ocp0000126

Dyrbye, L. N. \& Shanafelt, T. D. (2016). A narrative review on burnout experienced by medical students and residents. Medical Education, 50, 132-149.

Eliacin, J., Flanagan, M., Monroe-DeVita, M., Wasmuth, S., Salyers, M. P., \& Rollins, A. L. (2018). Social capital and burnout among mental healthcare providers. Journal of Mental Health, 27(5), 388-394. https://doi.org/10.1080/09638237.2017.1417570

Emerson, N. D., Merrill, D. A., Shedd, K., Bilder, R. M., \& Siddarth, P. (2017). Effects of an employee exercise programme on mental health. Occupational Medicine, 67 (2), 128-134. https://doi.org/10.1093/occmed/kqw120

Fleury, M.-J., Grenier, G., \& Bamvita, J.-M. (2017). A comparative study of job satisfaction among nurses, psychologists/psychotherapists and social workers working in Quebec mental health teams. BMC Nursing, 16, 1-12. https://doi.org/10.1186/s12912-017-0255-X

Galián-Muñoz, I., Ruiz-Hernández, J. A., Llor-Esteban, B., \& LópezGarcía, C. (2016). User violence and nursing staff burnout: The modulating role of job satisfaction. Journal of Interpersonal Violence, 31, 302-315. http://dx.doi.org/10.1177/0886260514555367

Garcia, H. A., McGeary, C. A., McGeary, D. D., Finley, E. P., \& Peterson, A. L. (2014). Burnout in veterans health administration mental health providers in posttraumatic stress clinics. Psychological Services, 11(1), 50-59. https://doi.org/10.1037/a0035643

Gavino, M. C., Wayne, S. J., \& Erdogan, B. (2012). Discretionary and transactional human resource practices and employee outcomes: The role of perceived organizational support. Human Resource Management, 51, 665-686. 10.1002/hrm.21493

Gevaux, N. S., \& Petty, S. (2018). Maximising resilience resources for mental healthcare staff. Mental Health Review Journal, 23(1), 37-53. https://doi.org/10.1108/MHRJ-10-2016-0020

Grace, M. K., \& VanHeuvelen, J. S. (2019). Occupational variation in burnout among medical staff: Evidence for the stress of higher status. Social Science \& Medicine, 232, 199-208. https://doi.org/10.1016/j.socscimed.2019.05.007

Gerberich, S. G., Church, T. R., McGovern, P. M., Hansen, H. E., Nachreiner, N. M., Geisser, M. S. Watt, G. D. (2004). An epidemiological study of the magnitude and consequences of work-related violence: The Minnesota Nurses' Study. Occupational and Environmental Medicine, 61, 495-503. http://dx.doi.org/10.1136/oem.2003.007294

Greenhaus J, Beutell N. Sources of conflict between work and family roles. Academy of Management Review. 1985; 10(1); 76-88

Havermans, B. M., Boot, C. R. L., Houtman, I. L. D., Brouwers, E. P. M., Anema, J. R., \& van der Beek, A. J. (2017). The role of autonomy and social support in the relation between psychosocial safety climate and stress in health care workers. BMC Public Health, 17, 1-7. https://doi-org.berlioz.brandonu.ca/10.1186/s12889-017-4484-4

Higgins, C., Duxbury, L., \& Julien, M. (2014). The relationship between work arrangements and work-family conflict. Work, 48(1), 69-81. https://doi.org/10.3233/WOR-141859 
Hinderer, K. A., VonRueden, K. T., Friedmann, E. et al. (2014). Burnout, compassion fatigue, compassion satisfaction, and secondary traumatic stress in trauma nurses. Journal of Trauma Nursing, 21, 160-169.

Jacobowitz, W. (2013). PTSD in psychiatric nurses and other mental health providers: A review of the literature. Issues in Mental Health Nursing, 34, 787-795. http://dx.doi.org/ $10.3109 / 01612840.2013 .824053$

Jian Li Wang. (2006). Perceived work stress, imbalance between work and family/personal lives, and mental disorders. Social Psychiatry \& Psychiatric Epidemiology, 41(7), 541-548. https://doi.org/10.1007/s00127-006-0058-y

Karadzinska, B. J., Basarovska, V., Mijakoski, D., Minov, J., Stoleski, S., Angeleska, N., \& Atanasovska, A. (2014). Linkages between workplace stressors and quality of care from health professionals' perspective - Macedonian experience. British Journal of Health Psychology, 19(2), 425-441. https://doi.org/10.1111/bjhp.12040

Kelloway, E.K., \& Hepburn, C. G. (2010). Early Employer Response to Workplace Injury: What Injured Workers Perceive as Fair and Why These Perceptions Matter. Journal of Occupational Health Psychology, 15(4), 409-420. https://doi-org.berlioz.brandonu.ca/ 10.1037/a0021001

Kelloway, E. K. (2018). Introduction to the special issue on Workplace Mental Health. Canadian Journal of Administrative Sciences (John Wiley \& Sons, Inc.), 35(4), 505-508. https://doi.org/10.1002/cjas.1516

Kendrick, K. D. (2017). The Low Morale Experience of Academic Librarians: A Phenomenological Study. Journal of Library Administration, 57(8), 846-878. https://doi. org/10.1080/01930826.2017.1368325

Kermott, C. A., Johnson, R. E., Sood, R., Jenkins, S. M., \& Sood, A. (2019). Is higher resilience predictive of lower stress and better mental health among corporate executives? PLoS ONE, 14(6), 1-14. https://doi.org/10.1371/journal.pone.0218092

Kirsh, B. (2000). Factors associated with employment for mental health consumers. Psychiatric Rehabilitation Journal, 24(1), 13-21. https://doi.org/10.1037/ h0095128

Kleiner, S., Schunck, R., \& Schömann, K. (2015). Different contexts, different effects?:Work time and mental health in the United States and Germany. Journal of Health and Social Behavior, 56(1), 98-113. https://doi org.berlioz.brandonu.ca/10.1177/0022146514568348

Kunst, A. E., Bos, V., Lahelma, E., Bartley, M., Lissau, I., Regidor, E., ... \& Helmert, U. (2004). Trends in socioeconomic inequalities in self-assessed health in 10 European countries. International Journal of Epidemiology, 34(2), 295-305.

Kurtessis, J. N., Eisenberger, R., Ford, M. T., Buffardi, L. C., Stewart, K. A., \& Adis, C. S. (2017). Perceived organizational support: A meta-analytic evaluation of organizational support theory. Journal of Management, 43, 1854 -1884. http://dx.doi.org/10.1177/014920 6315575554

Lamothe, J., Boyer, R., \& Guay, S. (2021). A longitudinal analysis of psychological distress among healthcare workers following patient violence. Canadian Journal of Behavioural Science / Revue Canadienne Des Sciences Du Comportement, 53(1), 48-58. https://doiorg.berlioz.brandonu.ca/10.1037/cbs0000187

LaMontagne, A. D., Milner, A. J., Allisey, A. F., Page, K. M., Reavley, N. J., Martin, A., ... Smith, P. M. (2016). An integrated workplace mental health intervention in a policing context: Protocol for a cluster randomised control trial. BMC Psychiatry, 16. Retrieved from 
http://search.ebscohost.com/login.aspx?direct=true \&db=psyh\&AN=2016-10752$001 \&$ site $=$ ehost-live

Laschinger, H. K. S., \& Grau, A. L. (2012). The influence of personal dispositional factors and organizational resources on workplace violence, burnout, and health outcomes in new graduate nurses: A crosssectional study. International Journal of Nursing Studies, 49, 282 291. http://dx.doi.org/10.1016/j.ijnurstu.2011.09.004

Li, L., \& Lee, Y. (2020). Employment adjustment and mental health of employed family caregivers in Canada. Aging \& Mental Health, 24(12), 2073-2081. https://doiorg.berlioz.brandonu.ca/10.1080/13607863.2019.1647136

Loretto, W., Platt, S., \& Popham, F. (2010). Workplace Change and Employee Mental Health: Results from a Longitudinal Study. British Journal of Management, 21(2), 526-540. https://doi.org/10.1111/j.1467-8551.2009.00658.x

Malachowski, C., Kirsh, B., \& Mceachen, E. (2017). The Sociopolitical Context of Canada's National Standard for Psychological Health and Safety in the Workplace: Navigating Policy Implementation. Healthcare Policy, 12(4), 10-17.

Marchand, A., \& Blanc, M.-È. (2011). Occupation, work organisation conditions and the development of chronic psychological distress. Work: Journal of Prevention, Assessment \& Rehabilitation, 40(4), 425-435

Marchand, A., Drapeau, A., \& Beaulieu-Prévost, D. (2012). Psychological distress in Canada: The role of employment and reasons of non-employment. International Journal of Social Psychiatry, 58(6), 596-604. https://doi.org/10.1177/0020764011418404

Martin, A., Karanika-Murray, M., Biron, C., \& Sanderson, K. (2016). The psychosocial work environment, employee mental health and organizational interventions: Improving research and practice by taking a multilevel approach. Stress and health, 32(3), 201-215.

Mattke, S., Liu, H., Caloyeras, J. P., Huang, C. Y., Van Busum, K. R., Khodyakov, D., \& Shier, V. (2013). Workplace wellness programs study. Santa Monica, CA: RAND Corporation

Milot, M. (2019). The impact of a Canadian external Employee Assistance Program on mental health and workplace functioning: Findings from a prospective quasi-experimental study. Journal of Workplace Behavioral Health, 34 (3), 167-191. https://doi.org/10.1080/ 15555240.2019.1609978

Moll, S. E., VandenBussche, J., Brooks, K., Kirsh, B., Stuart, H., Patten, S., \& MacDermid, J. C. (2018). Workplace Mental Health Training in Health Care: Key Ingredients of Implementation. Canadian Journal of Psychiatry, 63 (12), 834-841. https://doi.org/ $10.1177 / 0706743718762100$

Muntaner, C., Borrell, C., Benach, J., Pasarín, M. I., \& Fernandez, E. (2003). The associations of social class and social stratification with patterns of general and mental health in a Spanish population. International journal of epidemiology, 32 (6), 950-958.

Nishii, L. H., \& Wright, P. (2008). Variability at multiple levels of analysis: Implications for strategic human resource management. In D. B.Smith (Ed.), The people make the place (pp. 225-248). Mahwah NJ: Erlbaum.

Nørøxe, K. B., Pedersen, A. F., Bro, F., \& Vedsted, P. (2018). Mental well-being and job satisfaction among general practitioners: a nationwide cross-sectional survey in Denmark. BMC Family Practice, 19(1), N.PAG. https://doi.org/10.1186/s12875-018-0809-3 
Osborne, S. P., Z. Radnor, T. Kinder and I. Vidal (2015). 'The SERVICE framework: a public service-dominant approach to sustainable public services', British Journal of Management, 26, pp. 424-438.

Ott-Holland, C. J., Shepherd, W. J., \& Ryan, A. M. (2019). Examining wellness programs over time: Predicting participation and workplace outcomes. Journal of Occupational Health Psychology, 24(1), 163-179. https://doi.org/10.1037/ocp0000096

Read, E. A., \& Laschinger, H. K. S. (2015). The influence of authentic leadership and empowerment on nurses' relational social capital, mental health and job satisfaction over the first year of practice. Journal of Advanced Nursing, 71(7), 1611-1623. https://doiorg.berlioz.brandonu.ca/10.1111/jan.12625

Renwick, L., Lavelle, M., James, K., Stewart, D., Richardson, M., \& Bowers, L. (2019). The physical and mental health of acute psychiatric ward staff, and its relationship to experience of physical violence. International Journal of Mental Health Nursing, 28(1), 268-277. https://doi.org/10.1111/inm.12530

Rueda, S., Smith, P., Bekele, T., O’Brien, K., Husbands, W., Li, A., Jose-Boerbridge, M., Mittmann, N., Rachlis, A., Conyers, L., Boomer, K. B., \& Rourke, S. B. (2015). Is any job better than no job? Labor market experiences and depressive symptoms in people living with HIV. AIDS Care, 27 (7), 907-915. https://doi-org.berlioz.brandonu.ca/10.1080/ 09540121.2015.1015479

Schull, M., Guttmann, A., Leaver, C., Vermeulen, M., Hatcher, C., Rowe, B., . . . Anderson, G. (2011). Prioritizing performance measurement for emergency department care: Consensus on evidencebased quality of care indicators. Canadian Journal of Emergency Medicine, 13(5), 300-309. doi:10.2310/8000.2011.110334

Seung-Wan, K., \& Su-Dol, K. (2016). High-Commitment Human Resource Management and Job Stress: Supervisor Support as a Moderator. Social Behavior \& Personality: An International Journal, 44(10), 1719-1731. https://doi-org.berlioz.brandonu.ca/10.2224/ sbp.2016.44.10.1719

Shain, M., Arnold, I., \& GermAnn, K. (2012). The Road to Psychological Safety: Legal, Scientific, and Social Foundations for a Canadian National Standard on Psychological Safety in the Workplace. Bulletin of Science, Technology \& Society, 32(2), 142-162

Sheikh, M. S., Smail-Crevier, R., \& Wang, J. (2018). A Cross-Sectional Study of the Awareness and Implementation of the National Standard of Canada for Psychological Health and Safety in the Workplace in Canadian Employers: Une étude transversale de la notoriété et de la mise en œuvre de la Norme nationale du Canada sur la santé et la sécurité psychologiques en milieu de travail chez les employeurs canadiens. Canadian Journal of Psychiatry, 63 (12), 842-850. https://doi-org.berlioz.brandonu.ca/10.1177/0706743718772524

Shippee, T. P., Wilkinson, L. R., Schafer, M. H., \& Shippee, N. D. (2019). Long-Term Effects of Age Discrimination on Mental Health: The Role of Perceived Financial Strain. Journals of Gerontology Series B: Psychological Sciences \& Social Sciences, 74 (4), 664-674. https://doi.org/10.1093/geronb/gbx017

Slemon, A., Jenkins, E., \& Bungay, V. (2017). Safety in psychiatric inpatient care: The impact of risk management culture on mental health nursing practice. Nursing Inquiry, 24, e12199. http://dx.doi.org/10.1111/ nin.12199

Sockalingam, S., Soklaridis, S., Yufe, S., Rawkins, S., Harris, I., Tekian, A., Silver, I., \& Wiljer, D. (2017). Incorporating Lifelong Learning from Residency to Practice: A 
Qualitative Study Exploring Psychiatry Learners' Needs and Motivations. Journal of Continuing Education in the Health Professions, 37(2), 90-97. https://doiorg.berlioz.brandonu.ca/10.1097/CEH.0000000000000156

Szeto, A., Dobson, K. S., Luong, D., Krupa, T., \& Kirsh, B. (2019). Workplace Antistigma Programs at the Mental Health Commission of Canada: Part 1. Processes and Projects. Canadian Journal of Psychiatry, 64, 5S-12S. https://doi-org.berlioz.brandonu.ca/10.1177 /0706743719842557

Tianan Yang, Run Lei, Pei-Ru Li, Ai Yin Lim, Yangyang Sun, Jianwei Deng, Sheue-Rong Lin, \& Lai-Chu See. (2020). Moderated Mediation Model from Stress to Burnout among Health Professionals. American Journal of Health Behavior, 44(6), 765-779. https://doiorg.berlioz.brandonu.ca/10.5993/AJHB.44.6.3

Velez, B. L., Cox Jr., R., Polihronakis, C. J., \& Moradi, B. (2018). Discrimination, Work Outcomes, and Mental Health Among Women of Color: The Protective Role of Womanist Attitudes. Journal of Counseling Psychology, 65 (2), 178-193. https://doi.org/10.1037/ cou0000274

Wathen, C. N., MacGregor, J. C. D., \& MacQuarrie, B. J. (2018). Relationships Among Intimate Partner Violence, Work, and Health. Journal of Interpersonal Violence, 33 (14), 2268-2290. https://doi-org.berlioz.brandonu.ca/10.1177/0886260515624236

Zhao, S., Liu, H., Ma, H., Jiao, M., Li, Y., Hao, Y. Qiao, H. (2015). Coping with workplace violence in healthcare settings: Social support and strategies. International Journal of Environmental Research and Public Health, 12 (11): 14429-44. doi: 10.3390/ijerph121114429 